lasting longer than 36 months, none had normal language outcome. Multiple subpial transection should be considered if steroids are ineffective in the resolution of ESES by 36 months. (Robinson RO, Baird G, Robinson G, Simonoff E. Landau-Kleffner syndrome: course and correlates with outcome. Dev Med Child Neurol April 2001;43:243-247). (Respond: Professor RO Robinson, Newcomen Centre, Guy's Hospital, St Thomas Street, London SE1 9RT, UK).

COMMENT. In children with LKS the strongest predictor of outcome is the length of ESES. Those with recovery of language function have ESES for less than 3 years. Evolution of the syndrome is in 3 phases: 1) acute (few days to weeks) deterioration of receptive language with secondary deterioration in speech, seizures, mild behavior disturbance, centrotemporal EEG abnormalities awake and ESES in sleep; 2) chronic phase of aphasia and EEG abnormality lasting 1 to 7 years (mean 4 years), fluctuating seizures and worsening behavior disorder; and 3) stage of spontaneous improvement, occurring at a mean of 5 (range 1-9) months after resolution of ESES. Majority are left with various degrees of language impairment, particularly a verbal auditory agnosia, and full recovery is rare. Severe behavior problems (ADHD and ODD) are a common component of the syndrome and may be associated with frontal EEG abnormalities. AEDs are rarely effective and ESES is suppressed by steroids in only a minority of cases. Surgical intervention should be considered before ESES has persisted for $>3$ years.

Multiple subpial transection in L.KS. Five children, aged 5-10 years, with L.KS were treated surgically with multiple subpial transection at Guy's Hospital, London, UK ( Irwin K, Birch V, Lees J et al. Dev Med Child Neurol April 2001;43:248-252). Behavior, seizure frequency, and to a lesser degree language, improved dramatically after surgery in all patients treated. ESES was eliminated by the procedure. The timing of this intervention and its effect on language outcome needs further clarification.

\title{
LANGUAGE REGRESSION IN CHILDHOOD AUTISM
}

The clinical characteristics of 177 children ( $82 \%$ male and $18 \%$ female) with language regression were identified and studied prospectively at four medical centers: Montefiore and Albert Einstein, New York, NY; St Louis Children's, MO; Miami Children's, FL; and Yale University, CT. Mean age at language regression was 22.8 months (range 12-78 months). Triggers, including family stress, birth of a sibling, moving, seizures, and infection, were identified in $29 \%$. Time to referral to a specialist was 40 months (range 1 month to 14 years). Autistic spectrum disorder, definite (127) or suspect (28), was diagnosed in a total of $88 \%$. Language regression at a younger age ( $<36$ months) in 158 children correlated with a higher probability of autistic regression (91\%) than in the 19 with language regression after 36 months (58\%). Males with language regression developed autism more commonly than affected females (90\% and $75 \%$, respectively).

Seizures occurred in $18 \%$, and EEG abnormalities in $37 \%$. Seizures were more common in children who showed language regression at an older age (53\% of $14 \%$, respectively). Autistic regression was more common in children without seizures, especially after age 36 months. At the time of the last visit, language was impaired in $88 \%$, but some improvement had occurred in $57 \%$. Cognition was definitely abnormal in $28 \%$, and autism was present in $72 \%$. (Shinnar S, Rapin I, Arnold $S$ et al. Language regression in childhood. Pediatr Neurol April 2001;24:183-189). (Respond: Dr Shinnar, Epilepsy Mangement Center, Montefiore Medical Center, 111 E 210th St, Bronx, NY 10467). 
COMMENT. The loss of previously acquired language in young children is the most prominent feature of autistic regression and Landau Kleffner syndrome and requires early specialized evaluation and intervention. The most common age for regression to occur is in the second year, but referral to a pediatric neurologist or child psychiatrist is often delayed for 3 or 4 years, when regression has become more global and associated with cognitive and behavioral disorders, seizures, and autism. An EEG to rule out ESES and Landau Kleffner syndrome could lead to early steroid trials and possible surgical treatment. The occurrence of seizures and EEG abnormalities, often associated with autistic regression, might require treatment with antiepileptic drugs.

\section{ATTENTION DEFICIT DISORDERS}

\section{PRESCHOOL CHILDREN WITH ADHD}

Differences in behavioral, social, and school functioning of 58 preschoolage ( $3-5$ years) children with attention deficit/hyperactivity disorder and 36 normal controls were examined at Lehigh University, Bethlehem, PA. Parent and teacher behavior ratings showed more problem behavior and impaired social skills in ADHD children. The parents of ADHD children experienced greater stress, they were less adapted to coping, and were more likely to exhibit negative responses toward their children. ADHD children showed more negative social behavior in preschool settings, were more noncompliant, their behavior was inappropriate during task situations, and they scored significantly lower on a test of preacademic skills. (DuPaul GJ, McGoey KE, Eckert TL, VanBrakle J. Preschool children with attention-deficit/hyperactivity disorder: impairments in bahavioral, social, and school functioning. I Am Acad Child Adolesc Psychiatry May 2001;40:508-515). (Reprints: Dr DuPaul, School Psychology Program, Lehigh University, 111 Research Drive, Bethlehem, PA 18015).

COMMENT. Preacademic skills and preschool classroom behavior should be evaluated in young children with ADHD so that parent training techniques in child management may be taught and introduced early (see Ped Neur Briefs April 2001;15:28-29). Preschoolers with ADHD exhibit more than twice the level of noncompliance and five times the inappropriate behavior of control children when asked by parents to complete tasks. Parents' coping skills are also deficient and their responses more negative. Child disruptive and negative social behavior is common during unstructured, free-play activities in preschool classrooms. ADHD children have lower scores on cognitive tests and will enter school at an academic disadvantage, unless the problem is addressed early.

\section{PSYCHOSTIMULANTS IN PRESCHOOL CHILDREN WITH ADHD}

A retrospective chart review of 27 preschool children with $\mathrm{ADHD}$ who were treated with psychostimulants between 3 and 5 years of age, inclusive, was conducted at the Kennedy Krieger Institute, Johns Hopkins University School of Medicine, and the University of Maryland School of Medicine, Baltimore, MD. Methylphenidate (MPH) was given in 22 (82\%), dextroamphetamine in 4, and Adderal in 1. Eight were switched to an alternate stimulant during follow-up, because of inadequate response, side effects, or rebound. The mean $\mathrm{mg} / \mathrm{kg}$ daily doses and mean total daily doses of MPH were $0.55-1.16 \mathrm{mg} / \mathrm{kg}$ and $12-26 \mathrm{mg}$. Amphetamine doses were $0.43-0.6 \mathrm{mg} / \mathrm{kg}$ daily and $7.5-15 \mathrm{mg} /$ daily. A Clinical Global Impressions (CGI) scale to rate severity of ADHD showed significant improvements at 3,12 , and 24 months of treatment. Side effects were mostly mild, 